\title{
OS DESAFIOS DA EDUCAÇÃO: Intolerância e inconstitucionalidade do Manifesto à nação (FPE)
} do programa de governo de Jair Bolsonaro

\author{
Danielle do Nascimento Rezera ${ }^{\mathrm{i}}$ \\ Raquel Gomes D'Alexandre ${ }^{\mathrm{ii}}$
}

Resumo: O artigo analisa o documento intitulado "Manifesto à nação: o Brasil para os brasileiros", elaborado pela Frente Parlamentar Evangélica - FPE, no ano de 2018, e suas implicações ao regimento jurídico estabelecido pela Lei ${ }^{\circ}$ 9.394/96. Com o intento de verificar se a figura do direito público subjetivo presta-se à exigibilidade de nossa Constituição Federal de 1988 no cenário em que há forte influência dos quadros da bancada evangélica na proposição de medidas políticas para a Educação. O "Manifesto" foi direcionado ao Governo de Jair Bolsonaro tendo em vista a execução de um conjunto de propostas para a condução das políticas públicas da área. Concluiu-se demonstrando as amarras dos interesses políticos e ideológicos envolvidos na presunção de um novo modelo de Educação.

Palavras-chave: Políticas Públicas Educacionais, Direitos Sociais, Estado Laico.

\section{THE CHALLENGES OF EDUCATION: Intolerance and unconstitutionality of the Manifesto to}

\section{the Nation (FPE) of Jair Bolsonaro's government program}

\begin{abstract}
The article analyzes the document entitled "Manifesto to the Nation: Brazil for Brazilians", prepared in 2018 by the Frente Parlamentar Evangélica (Evangelical Parliamentary Front)- FPE. And its implications for the legal regiment established by Law 9,394 / 96, in an attempt to investigate whether our subjective public right lends itself to the enforceability of our Federal Constitution of 1988 in the context in which there is strong influence of the evangelical parliamentary benches in the proposition of political measures for the area of Education. The "Manifesto" was addressed to the Government of Jair Bolsonaro in order to implement a set of proposals to conduct the public policies of the area. Conclusions show the interdependence of the political and ideological interests involved in the assumption of a new model of Education
\end{abstract}

Keywords: Educational Politics, Social Rights, Laic State 


\section{Introdução}

O presente artigo destina-se ao exame da figura do direito público subjetivo previsto no art. $208, \S$ $1^{\circ}$ da Constituição Federal Brasileira de 1988, para normatizar o acesso ao ensino obrigatório e gratuito que estabelece a exigibilidade de políticas públicas educacionais. Para tanto, serão analisadas as condições de adaptabilidade do discurso presente nas propostas políticas direcionadas ao novo Governo de Jair Messias Bolsonaro (2019) no quadro da crescente influência dos grupos religiosos que tem, conforme vemos na composição de nossos representantes políticos e suas pautas, assumido expressividade e maior poder de interferência em questões relacionadas à dimensão da Cultura e da Educação do país.

A partir da análise documental e abordagem comparativa entre a literatura dos pressupostos constitucionais e históricos da nossa sociedade, quanto à educação e ao maniqueísmo político em torno dessa base tão cara ao nosso futuro, nossa cidadania e direitos, utilizamos-nos do documento produzido pela Frente Parlamentar Evangélica - FPE intitulado "Manifesto à nação: O Brasil para os brasileiros" (2018) para questionar em que medida o direito público subjetivo é aplicável quando analisadas as diretrizes políticas voltadas para as políticas públicas de educação. No quadro em que há forte influência do lobby evangélico para a condução dos princípios éticos e morais que irão nortear os costumes sociais em diferentes categorias de ensino. Frente a esse cenário, é pertinente verificar se as práticas políticas desempenhadas por tais grupos se coadunam aos princípios e finalidades de nosso ordenamento jurídico consoante ao Estado Social e de Direito estabelecido em nossa Constituição Federal.

\section{Estado, Direito Público Subjetivo e Objetivo: consequências para as práticas e formulações das políticas educacionais.}

Ao trabalhar com os elementos que compõem a Teoria Geral do Estado, Dallari (1998) ressalta os aspectos que são fundamentais à lógica de funcionamento e organização social em que se compõe "a ordem jurídica soberana que tem por fim o bem comum de um povo situado em determinado território" (1998, p. 44). Sob essa perspectiva, Santos (2012) categoriza o Estado como um ente que:

[...] corresponde a uma estrutura que transcende os indivíduos e as coletividades, que é impessoal e que arbitra as regras e normas (convertidas muitas vezes em leis) estruturadoras da sociedade. Entre outros motivos, o Estado existe para, de acordo com leis, regras e normas, distribuir poder - ou permitir o acesso a ele - e recursos a cada um dos componentes da sociedade, sejam estes indivíduos, grupos ou organizações (SANTOS, 2012, p. 4).

Nessa dimensão o Estado se caracteriza por sua função mediadora entre as leis e os indivíduos, que agem de maneira dialética no sentido de se adequar às necessidades prementes de uma organização social caracterizada por disputas no quadro de poder. Essa perspectiva coloca em destaque uma categoria basilar 
para a análise que compõe o entendimento do que seria o poder. Ou seja, em face dos delineamentos atribuídos ao Estado, o poder, numa perspectiva weberiana, incide em "toda probabilidade de impor a vontade numa relação social, mesmo contra resistências, seja qual for o fundamento dessa probabilidade" (WEBER, 1991, p.33), pela qual aqueles que detêm a capacidade ou a propriedade de obrigar um indivíduo, ou grupo social, a realizar alguma ação mediante o uso da persuasão ou coação, visando um fimm no âmbito das relações sociais no qual se afigura o conjunto dos campos políticos.

A esse respeito, Pierre Bourdieu (1998), ao analisar a conformação dos sistemas simbólicos que envolvem as disputas consolidadas no campo político, estabelece que a lógica de construção do discurso se consubstancia no fator de integração social voltado ao consenso, a julgar que o consenso apresentado é o da hegemonia, ou seja, aquele voltado para a elaboração do discurso de dominação. De modo que, "as relações de comunicação são, de modo inseparável, sempre, relações de poder que dependem na forma e no conteúdo do poder material e simbólico acumulado pelos agentes” (BOURDIEU, 1998, p. 11). Assim, o que ocorre é uma relação de luta, principalmente simbólica, que as diferentes classes estão envolvidas para impor "a definição do mundo social conforme seus interesses" (Ibidem).

A configuração do cenário político apresentado com a eleição de um candidato que desde sua campanha política esteve articulado aos interesses da bancada evangélica torna-se um elemento elucidativo da forma pela qual os agentes envolvidos atuam no campo político visando um maior poder de representação. Perceba que a categoria representação se torna basilar à compreensão dos campos de luta na proposição de uma reforma política do Estado na qual a educação se apresenta como fator determinante à construção de um projeto de Estado Nacional. Na perspectiva de Roger Chartier (1990) a representação se constitui em elemento fundamental para a compreensão das relações entre os grupos que a forjam. Visto serem determinadas pelos interesses dos grupos que a compõe, estes agem no sentido de delimitar as formas de ver e agir no mundo, como se a configuração da realidade necessariamente devesse submeter-se à conformação de seus interesses. Daí podemos observar os embates entre grupos para prevalecer a visão de mundo de um deles:

As percepções do social não são de forma alguma discursos neutros: produzem estratégias e práticas (sociais, escolares, políticas) que tendem a impor uma autoridade à custa de outros, por elas menosprezados, a legitimar um projecto reformador ou justificar, para os próprios indivíduos, as suas escolhas e conductas (...) As lutas de representações têm tanta importância como as lutas econômicas para compreender os mecanismos pelos quais um grupo impõe, ou tenta impor, a sua concepção do mundo social, os valores que são seus, e o seu domínio (CHARTIER, 1990, p. 17).

Por não assumir caráter neutro em seus princípios e reivindicações, as lutas devem se utilizar dos mecanismos do ordenamento jurídico e de funcionamento do Estado para executar os seus planos de governo. De modo que, o projeto político desenvolvido pela Frente Parlamentar Evangélica - FPE denominado "Manifesto à nação: O Brasil para os brasileiros" (2018) se apresenta como um verdadeiro 
conjunto de sistemas simbólicosiii a atuar na propagação de discursos políticos que contemplam setores relacionados aos interesses de grupos neopentecostais e vêm desenvolvendo uma hegemonia no campo de disputa política e, a partir deste governo, se articulam de modo mais ferrenho pautando as demandas sociais e a forma de atuação do Estado por meio de uma ordem moral.

Defronte ao jogo de disputas, a questão da configuração do direito público subjetivo - como uso do instrumento jurídico para a garantia do direito individual, bem como na asseguração do bem coletivo aparentemente se torna um alvo frágil frente à garantia dos direitos fundamentais que compõe a ordem jurídica soberana, quando pensada a representatividade política cujo Partido Social Liberal - PSL assume no cenário de eleição do atual presidente, igualmente da ascensão da FPE. Nesse quadro surge a questão: no que consiste o direito público subjetivo? Segundo Clarice Duarte:

\begin{abstract}
trata-se de uma capacidade reconhecida ao indivíduo em decorrência de sua posição especial como membro da comunidade, que se materializa no poder de colocar em movimento normas jurídicas no interesse individual. Em outras palavras, o direito público subjetivo confere ao indivíduo a possibilidade de transformar a norma geral e abstrata contida num determinado ordenamento jurídico em algo que possua como próprio. A maneira de fazê-lo é acionando as normas jurídicas (direito objetivo) e transformando-as em seu direito (direito subjetivo) (DUARTE, 2004, p.115).
\end{abstract}

O interessante dessa definição é notar que esse direito emana da configuração de um Estado Liberal que resguarda os direitos individuais mediante o uso dos instrumentos jurídicos frente ao poder de controle e atuação do poder estatal, impondo-lhe limites de ação bem como permitindo ao seu titular obrigar o Estado a executar o que deve. A partir dessa concepção fica claro que a eleição de Bolsonaro para presidente, ocorrida no ano de 2018, apresenta um divisor de águas importante, ao incorrer em constantes tentativas de implosão do Estado Democrático de Direito via procedimentos institucionais.

A afirmativa incide em uma série de eventos políticos transmitidos por distintos veículos de informação, denotando a configuração de um modelo de governo de vertente conservadora ${ }^{\text {iv }}$, no que tange ao combate às liberdades individuais, de manifestação das crenças, dos costumes e da condução da vida privada, bem como na definição dos valores que serão transmitidos via institucional, como no caso da educação. Em virtude disso, a proposição de metas pelo novo Governo merece atenção no que se refere à transmissão dos valores sociais voltados para a homogeneização de um padrão social de comportamento a ser adotado, inclusive, pela escola.

\title{
O governo Jair Bolsonaro e a educação como base moral cristã neopentecostal alicerçado no Manifesto à nação: $O$ Brasil para os brasileiros
}

Em documento intitulado "Manifesto à nação: O Brasil para os brasileiros" (2018), elaborado pela $\mathrm{FPE}^{\mathrm{v}}$ e encaminhado ao respectivo presidente, é possível apreender a sua organização em quatro frentes 
das quais caracterizam como principiológicos, sendo "[...] um verdadeiro planejamento estratégico. Fundado sobre os eixos 'Modernização do Estado, Segurança Jurídica, Segurança Fiscal e Revolução na Educação"” (MANIFESTO À NAÇÃO, 2018, p. 02), o plano busca soluções para o desenvolvimento nacional, no qual a modernização do Estado está diretamente relacionada a uma revolução no quadro da educação e dos valores da nação:

assim, ora viemos a público apresentar a síntese analítica de tal projeto, demonstrando os valores-base que orientaram sua confecção, assim como alguns exemplos de medidas de sua aplicação concreta. Com isso, esperamos dar a contribuição dos parlamentares da Frente Parlamentar Evangélica para o Novo Brasil que todos queremos. Viva o povo brasileiro! Que Deus abençoe o Brasil! Feliz a nação cujo Deus é o SENHOR. S1, 33:12, b (MANIFESTO À NAÇÃO, 2018, p. 02).

A Educação no Brasil perpassou uma série de trajetos em sua história (a Escola Nova nos anos de 1920; os movimentos que levam à formulação de Leis Orgânicas do Ensino, nos anos de 1940; entre os anos de 1960 aos 1980, a criação do Movimento Brasileiro de Alfabetização; criação da UNE; introdução de novas práticas pedagógicas com o pensamento paulofreiriano), caminhos que a partir da constituição cidadã de 1988 rumaram para um desenvolvimento de um projeto educacional plural, participativo e que amplia o acesso aos processos e etapas educacionais. Atualmente, no entanto, vemos que a leitura dos direitos constitucionais diversos e os ligados à educação vêm sendo reiteradamente corrompidos, ignorados e estigmatizados dentro de uma lógica intolerante, fascista e fundamentalista, tendo como pretexto um expurgo de "ideologias de esquerda" presentes na atuação das políticas públicas e práticas educacionais. Estas visam combater a desigualdade, violências e os padrões de baixo desenvolvimento advindas de sociedades assimétricas. Portanto, ampliar o contingente de profissionais qualificados para o mercado de trabalho, entre tantas questões urgentes, seria atender o que preconiza a Constituição de 1988 e a LDB de 1996, bem como seus adendos e emendas.

Ocorre que o fascínio exercido pelo rompimento das bases institucionais de direitos sociais no Brasil tem sido uma bandeira levada por grupos de parlamentares, pensadores de extrema-direita, imbuídos na mentalidade social, a partir de processos comunicativos e de aderência no escopo ideológico e religiosos, que tem figurado uma verdadeira marcha contra a educação e seus predicados socioeconômicos.

Tendo em vista as recentes declarações sobre a educação no Brasil e a proposta de reforma persecutória, dada pelo presidente Jair Bolsonaro, via a rede social Twitter, em 4 de março de 2019 ${ }^{\text {vi }}$, compreendemos que parte do processo exposto acima lançou cortes na educação, ou no "excesso" de gastos com esta pasta, procurando reproduzir, no âmbito acadêmico, uma espécie de Lava Jato ideológica dos estudantes e universidades brasileiras, questões também explicitadas no Manifesto da Frente Evangélica, contendo as mesmas argumentações e proposições. 
Um projeto ultraliberal sob a ótica de desmontes contínuos, que tem como predecessor o projeto "uma ponte para o futuro",vii do governo de Michel Temer (2016-2018), em que há uma série de distratos sociais e constitucionais, que incluíam as PECs 241-55/2016. Estas refletem 20 anos de enxugamento dos investimentos básicos e a reforma do ensino médio, que está inserida na MP 746/2016, com amplo apoio de proponentes do projeto "Escola Sem Partido" viii e de parlamentares que permaneceram no atual governo. Estes subvertem a não adesão ao projeto pela população, conforme a consulta pública da matéria ${ }^{\mathrm{ix}}$ em que 94\% dos votos são contrários à referida medida. Assim como desconsideram a participação das entidades diversas e entes civis que atuam e pensam o setor educacional e suas políticas, do mesmo modo como seus manifestos, pesquisas e suportes para a área.

Assumindo a concepção na qual o Estado possui a condição de soberania que transcende as vontades individuais e coletivas, como é possível apreender a imersão dos grupos evangélicos na delimitação das diretrizes políticas para a Educação? Ao se pensar na constituição do Estado Social de Direito, na qual a educação se torna um dos componentes essenciais ao pleno desenvolvimento social humano, tais grupos se comprometem a delinear as novas diretrizes políticas educacionais a ser consolidadas pelo Governo por meio da configuração de um discurso social cristão como equivalentes à vontade e necessidades da nação.

No entanto, a composição do ordenamento de um Estado Liberal Clássico, do qual nossa Constituição Federal de 1988 é herdeira, estabelece como um de seus princípios “a condição de exigibilidade individual de direitos civis e políticos" calcada no "reconhecimento de uma posição jurídica que confere aos seus titulares a possibilidade de barrarem qualquer intervenção estatal indevida em sua esfera própria de liberdade" (DUARTE, 2004, p. 114). A autora retoma a questão sobre as competências do Estado em sua dimensão jurídica, retomando o problema da atuação do direito público subjetivo como instrumento de resguardo dos direitos individuais em relação ao que se atribui enquanto decisão política.

Afinal, o procedimento de formulação e desenvolvimento das políticas, sejam elas direcionadas a qualquer uma das áreas sociais, deve estar voltado ao cumprimento dos objetivos e programas de ação governamental previstos no artigo $6^{\circ}$ da Constituição Federal de 1988, que são inalienáveis. Assim, a execução de uma política que não prima por tais princípios se caracteriza por sua arbitrariedade. Neste caso, a atuação do direito público subjetivo emana no sentido de blindar o indivíduo contra possíveis abusos que o Estado executa frente à delimitação da sua esfera de liberdade.

De acordo com esta concepção, o que se pretende é uma omissão (conduta negativa) dos Poderes Públicos: não agir de forma arbitrária, ou seja, desrespeitando os parâmetros legais previamente estabelecidos. Entretanto, a busca por um patamar mínimo de igualdade, não apenas jurídica mas também material e efetiva - grande bandeira dos direitos sociais -, exige uma posição ativa do Estado no que se refere à proteção de direitos, pois o que se pretende é criar, por parte dos Poderes Públicos, condições concretas de vida digna (DUARTE, 2004, p. 114). 
Contudo, a lógica apresentada no Manifesto à nação (2018) se baseia num pretenso Brasil para os brasileiros, composto de uma agenda mínima, que visa retirar o "monopólio" de poder dos entes partidários. Uma clara manifestação de um Estado não democrático engendrado por grupos descompromissados com padrões mínimos de segurança jurídica e constitucional dos direitos.

É uma reconfiguração do papel do Estado e seus sistemas regulatórios e, claramente, uma estratégia de privatização generalizada de setores fundamentais da economia e desenvolvimento do Brasil. Propõe-se um amplo programa de enfraquecimento ou desaparecimento de instituições consolidadas e fundamentais, assim como da performance do Estado frente às demandas sociais, reforçando a necessidade de atuação do Estado a favor dos ditames do mercado. Com amplo discurso moral-cristão, o documento justifica seu interesse para a sociedade, alegando que a mesma é majoritariamente cristã, criando uma farsa em relação ao real conteúdo do documento e intenções.

Fundado sobre os eixos denominados como modernização do estado, segurança jurídica, segurança fiscal e revolução na educação, o plano propõe uma transformação do sistema político brasileiro, bem como utiliza-se de argumentos ligados ao fraco ou incipiente desenvolvimento nacional e à corrupção. Os referidos eixos "são conceitos que uma vez aplicados na condução dos negócios de Estado, se retroalimentam em um círculo virtuoso, propiciando estabilidade econômica e institucional perenes, associadas ao desenvolvimento econômico e social substantivo" (MANIFESTO À NAÇÃO, 2018, p. 2).

Aponta que o principal objetivo é, através da redução de custos e de intervenção/regulação do Estado, ampliar a eficiência da máquina pública e garantir ao povo empreendedor brasileiro um "espaço ao sol”, ou seja, oportunidades, num amplo sistema de parcerias PPI (Programa de Parcerias e Investimentos), privatizações e sistemas regulatórios mais afrouxados nos mais variados setores, como saúde, seguridade, educação e meio ambiente. Ou seja, vemos setores fundamentais para o controle do Estado serem alocados em interesses diversos e divergentes daqueles que preconizam o interesse de uma sociedade assegurada em seus direitos fundamentais. No plano educacional, ocorre amplo processo de desinvestimento do Estado no setor, implementando privatizações e parcerias diversas.

A pretensa "Revolução da Educação" passa por diversos ataques ao direito de acesso, de qualidade e de ampliação do direito à educação. Desconsidera não só as diretrizes constitucionais como os processos intrínsecos do fazer educacional e seus desafios, conforme nos aponta Paro (2016, p.38) ao tratar das “diversas violências cíclicas que envolvem abusos das crianças e jovens pela sua condição econômica, social e de gênero. Essas pessoas vão para a escola e têm o direito de ter sua história e sua subjetividade respeitadas no considerado processo educativo".

No mesmo sentido, há preservação da liberdade quando as imposições morais são transferidas e reguladas no campo jurídico. Assim, com Habermas (2014, p.114) o direito organizado como sistema retira dos indivíduos "o fardo das normas morais e as transfere para as leis que garantem compatibilidade das 
liberdades de ação", tolhe tais liberdades validando-as ou não no escopo da totalidade social, regulando o encontro das vontades no espaço público, tornando o entrelaçamento das vontades internas e externas ligadas aos subsistemas sociais e suas diversas manifestações morais e culturais a um ordenamento de decisões de razão prático-moral. Portanto, as razões que se apregoam no atual governo giram em torno de concepções de grupos econômicos ultraliberais e religiosos conservadores que compreendem a educação como um negócio e fundamentalmente rompem alicerces das vontades do espaço público, para construir bases das vontades de cunho privado/corporativo. Paro (2016) nos apresenta um resumo do estado da coisa:

a escola que nós temos acaba sendo efetiva simplesmente por não fazer nada. O objetivo escondido é o objetivo das classes dominantes, mas não é um objetivo educativo, é simplesmente um objetivo de dominação social. A verdadeira função da escola, todo mundo sabe disso, tem sido legitimar a inferioridade dos inferiores, garantir a dominação sobre as populações que mais precisam da escola, das camadas trabalhadoras que contabilizam dezenas de milhões. A essa população não se tem dado praticamente nada. (PARO, 2016, p.43).

A esse nada, resgatamos o princípio do que entendemos ser a função econômica da escola pública, ou seja, assegurar muito além do status quo da desigualdade retroalimentada por programas de parcerias privadas, os quais retiram do erário público os parcos subsídios da educação e o reorganizam na lógica das privatizações, ou seja, o nada da educação é o muito das corporações e seus entes representativos na esfera política.

\section{Manifesto à nação, a revolução na educação.}

Diversas concepções são alicerçadas sobre a educação no eixo quatro do Manifesto, intitulado "a revolução na educação". Uma delas diz respeito à lógica laboral, quer dizer, a criação de uma sociedade capaz de atender a demanda do mercado de trabalho, incrementado pela adoção de investimentos ainda mais baixos em industrialização e tecnologia, pejorativas reformas educacionais, trabalhistas e previdenciária, além da ampliação da atuação do setor financeiro especulativo. Desse modo, vislumbramos um cenário de informalidade, de acesso ao trabalho em áreas de baixa qualificação e/ou em qualificação técnica, em que o engodo da promoção à educação por meritocracia pretensamente oportunizaria o acesso aos níveis mais elevados na educação. Na realidade, desconsidera claramente a história da educação brasileira e suas peculiaridades sociopolíticas, os níveis de desigualdade econômica e social, assim como as lutas sociais em prol de uma nação com oportunidades e direito de acesso, como apregoa a Constituição brasileira em seu artigo $208^{\mathrm{x}}$. E, essencialmente, o artigo $206^{\mathrm{xi}}$, que estabelece oito princípios base da educação brasileira, e assegura os direitos em torno da qualidade do ensino plural e da valorização do professorado.

De modo geral, a questão que se alicerça é de uma ideologia da competência já extensamente discutida pela filósofa Marilena Chauí (2014). A autora alerta sobre a ideologia do autoritarismo neoliberal 
no percurso histórico da lógica do trabalho, que compreende a educação como um instrumento para as corporações e para atendimento do mercado, desconsiderando, segundo a pensadora, a formação de qualidade não só técnica como crítica e capaz de desenvolver a qualidade social e econômica. Outra questão fundamental do Manifesto versa sobre uma pseudoideologia de gênero ${ }^{\text {xii }}$ totalitária, sendo empregada nas escolas por governos de esquerda e um pseudototalitarismo comunista, que enfraqueceria o ensino e o desenvolvimento tecnológico brasileiro, pois as escolas e seus currículos se baseiam na pluralidade e direito do educando em aprender a aprender, por exemplo.

Segundo o texto, a adoção de uma "escola sem partido" faz parte do referencial de salvação das mentes em formação, e é o que o novo governo de fato tem apresentado com as representações no corpo político e técnico do MEC, nas figuras do novo ministro da educação Abraham Weintraub, nomeado em 8 de abril de 2019; bem como do ex-ministro Ricardo Velez, que alegava que as "universidades devem ficar reservadas para uma elite intelectual", "não é para todos", e Iolene Lima, que ao ser convidada a chefe executiva da pasta de Educação do MEC, passa a ser conhecida do público por um vídeo que circula na internet mostrando sua cosmovisão cristã na educação, "em que o aluno vai aprender que o autor da história é Deus, o autor da geografia é Deus (...)" xiii.

Ora, se desde sua formulação, a Constituição de 1988 visa instituir:

um Estado Democrático, destinado a assegurar o exercício dos direitos sociais e individuais, a liberdade, a segurança, o bem-estar, o desenvolvimento, a igualdade e a justiça como valores supremos de uma sociedade fraterna, pluralista e sem preconceitos, fundada na harmonia social e comprometida, na ordem interna e internacional, com a solução pacífica das controvérsias, promulgamos, sob a proteção de Deus, a seguinte CONSTITUIÇÃO DA REPÚBLICA FEDERATIVA DO BRASIL. (Preâmbulo Constituição Federal, 1988).

Como é possível cercear o direito individual e social, assim como a liberdade e igualdade num estado teocrático proselitista que desconsidera a diversidade religiosa ou a-religiosa da sociedade em que se situa? O que é moralmente aceito no contexto social não necessariamente faz ponte aos conceitos éticos da lógica idealista objetiva. Hegel (1980, p. 377) trata a moral como sendo uma questão objetiva e social, portanto tem de se pautar pela ética. Vejamos que o preâmbulo da Constituição anuncia intenções, seus objetivos e dá sentido à finalidade do referido documento que segue com normativas e diretrizes para o funcionamento da sociedade brasileira.

Atenta, conforme art. $5^{\circ}$, inciso VI, que é inviolável a liberdade de consciência e de crença, sendo assegurado o livre exercício dos cultos religiosos e garantida, na forma da lei, a proteção aos locais de culto e a suas liturgias. Já o art. 19, inciso I, preconiza que é vedado ao Poder Público estabelecer cultos religiosos ou igrejas, subvencioná-los, embaraçar o funcionamento ou manter com eles ou seus representantes relações de dependência ou aliança, ressalvada, na forma da lei, a colaboração de interesse público. Aqui 
verificamos que o estado subvenciona diversos grupos religiosos por meio de imunidade tributária, desde a Constituição de 1946, para os "templos de qualquer culto", "desde que as suas rendas sejam aplicadas integralmente no País para os respectivos fins".

O estado brasileiro se apresenta como laico, conforme o art. $5^{\circ}$, inciso VI e assegura a existência e promoção das religiões e suas manifestações, destina a liberdade fundamental de crença e culto em locais próprios, tanto é que abdica a cobrança de impostos para dar ampla possibilidade de uso desse direito, e permite-lhes o espaço próprio para tal fim.

Ocorre que o senso comum atribui à dimensão do Estado laico (do GREGO, significa leigo ou distante do clerical) como algo negativo, que afasta a moral cristã e os bons costumes da esfera pública, como se as esferas dos direitos e dos deveres fossem subjetivas e o senso moral único. Tais discursos se ampliam constantemente no cerne da vida política de nosso país, a fim de ampliar o lugar de grupos religiosos e suas corporações nos espaços decisórios, no que tange a vida privada e social dos indivíduos, cerceando direitos básicos, historicamente conquistados por expressiva luta social, e pautando as manifestações políticas por um senso antiplural e antidemocrático.

A laicidade, no entanto, denota a neutralidade do Estado em exclusão da religião da esfera pública, e refere-se também à imparcialidade do Estado com respeito às religiões, ou seja, através da prática da laicidade, implica-se no Estado o direito às religiões e suas manifestações diversas como, também, assegura ou deveria assegurar um Estado que se pautará em suas decisões políticas via referências de cunho social, econômico e constitucional, entre outros. Para Bobbio (2010) nada mais que uma representação de uma pluralidade cultural assegurada.

Ao transferirmos a perspectiva de um estado laico à educação, estamos desvelando uma jornada histórica de embates entre setores religiosos e o mundo que se transforma pelas necessidades do trabalho, em que o embate de forças se amplia desde a modernização da sociedade francesa (RUSSAR, 1988; BRANCHO, 2005; ZUBER, 2010).

É importante frisarmos que neste âmbito de debate a disputa pelo controle social e político por meio da educação é, historicamente, objeto de desejo e contenda entre os entes sociais diversos. Muito do interesse parte do princípio de uma escola que seja incapaz de interagir socialmente com seus conflitos e problemas ao redor, assim como do processo de disputa no debate social, político, cultural e econômico do país.

Tendo a concepção de que o indivíduo é historicamente alçado à sua condição por uma série de mudanças e embates ideológicos, Marx (2011, p. 45) atenta, como um dos problemas de compreensão da sociedade complexa, à leitura da individualização no direito e no trabalho, pois este indivíduo está dentro de uma totalidade, inserido numa classe e sofre determinações da realidade em que se situa e influências 
das categorias a que está sujeito, a moral e a ética da classe dominante. Nesse sentido, esta define os sistemas e os modos participativos da população.

Essa disputa é na sua essência uma guerra contra a população e uma contenda ideológica a respeito da instrumentalização dos educandos às demandas do mercado de trabalho e consumo e entes de poder, principalmente quando estamos numa política autoritária e fundamentalista, cuja tendência é um controle austero do currículo educacional baseado em preceitos religiosos de uma só vertente e que tende a se estender aos setores culturais e produtivos, o que incorre num processo persecutório aos profissionais e demais correntes pró-democráticas e pró-pluralidade e qualidade na educação.

As reformas da base da direita brasileira, agora com o personagem político Jair Bolsonaro e sua base fundamentalista e ultraliberal, visam ampliar os sistemas de desigualdades no escopo social e econômico, visto que o modelo de educação pode ser direcionado ao atendimento de setores de trabalho precário, e que não atrelam inovação e autonomia tecnológica e produtiva a nossa sociedade. É o que vemos, por exemplo, na proposta de base educacional cívico-militar, amplamente defendida pelo presidente Jair Messias Bolsonaro, principalmente para as escolas que apresentam baixos índices de desenvolvimento. Entretanto, para o educador Luiz Carlos de Freitas ${ }^{\text {xiv }}$ é:

descaradamente política de homogeneização de valores conservadores com a desculpa de que a 'ordem' leva ao 'progresso' (para os pobres). Os ricos já têm o progresso, pois em algum momento tiveram ordem, vale dizer, disciplina. Como diria Miguel Arroyo, há aí um 'padrão de desumanização' excludente. (FREITAS, 2019, O Jornal de Todos os Brasis, Política).

Em diversas falas do presidente e de sua equipe, há um consenso de que há algo de muito sórdido na educação brasileira. Eles atribuem ao Estado a ineficiência nos resultados, pois teria propiciado políticas públicas de caráter comunista, socialista, assim fomentado debates de cunho amoral no seio escolar. A razão de tais ataques aos setores sociais e àqueles que privilegiam transformações sociais qualitativas bem como, desde a Constituição cidadã de 1988 e a promulgação da Lei de Diretrizes e Bases de 1996, se mobilizam a fim de valer os preceitos legais de acesso, diversidade, pluralidade, criticidade, ampliação de jornada escolar, programas de alimentação, de ampliação de materiais didáticos/paradidáticos, compromissos didático-pedagógicos, formação de profissionais qualificados, como também a ampliação da participação da sociedade no fazer escolar — é o mascaramento dos índices e indicadores educacionais no Brasil.

Uma leitura acurada das mais diversas possibilidades e particularidades que o ensino no Brasil apresenta faria uma revolução necessária por um viés absolutamente contrário ao sugerido e em implementação pelo atual governo. Por um lado, teria de reconhecer as ingerências da máquina pública, 
combater a corrupção, os lobbies das bancadas que o sustentaram no processo eleitoral e apoiam sua permanência. Do mesmo modo, questionar duramente o lobby para a precarização do ensino público e a fábrica de "depósito de gente", pois este grupo de pressão está organizado de modo a evitar o desenvolvimento de jovens e crianças. Ou seja, seus agentes e prepostos buscam ampliar o mercado e a fatia dos recursos públicos da educação para redirecionar tais verbas aos setores privados que representam.

A premissa do discurso da privatização se encontra no baixo desempenho do Brasil em variados índices do setor educacional, porém o que eles demonstram é uma gama de indicadores e dados que nos permitem observar a raiz do problema. O atual governo, no entanto, observa o quadro generalizado, desconsiderando as implicações das especificidades dos dados e seus indicadores.

Desse modo, podemos constatar como os indicadores levantados pelo Education at a Glance (EaG) em $2018^{\text {xv }}$, da Organização para Cooperação e Desenvolvimento Econômico (OCDE) —estudo comparativo dos índices de 40 países sob a perspectiva da equidade na educação, com uma análise de comparabilidade entre os países à luz de aspectos como impacto da aprendizagem, acesso à educação, recursos financeiros investidos na educação, professores, ambiente de aprendizagem e organização das escolas - contribuem com elementos para a reflexão.

De fato, o Brasil apresenta uma distância grande frente a outros países desenvolvidos, porém o estudo esmiúça uma série de variáveis do processo educacional e seus resultados, mostrando um déficit ainda pernicioso no padrão de permanência e continuidade dos estudos nas faixas de 25-34 anos, que se configura com $36 \%$ de não conclusão do ensino médio, o que para o mercado de trabalho brasileiro configura uma perda de permeabilidade de $17 \%$ para homens e $50 \%$ para mulheres. Ao inferirmos o número de não concluintes com as taxas de adesão ao mercado, chegamos à conclusão de que são atividades de baixa qualificação profissional. Aponta uma alta proporção de alunos na educação infantil e básica por professor, que chega à diferença de até $50 \%$ a menor nos países com melhor desempenho.

Indica que no Brasil a adesão ao ensino superior foi o que mais se aproximou dos países desenvolvidos. Todavia, no que concerne a perspectiva de Jair Bolsonaro ao ensino superior, há uma crítica à metodologia didática, ao professor-pesquisador-orientador, que na sua gama de atribuições e produção, segundo o documento Manifesto à nação, acrescenta pouco à pesquisa e ao desenvolvimento do país. O documento em questão não procura elucidar os problemas estruturais da educação, pois parece objetivar aprofundar os danos na área.

Já o Fórum em Defesa da Educação Superior Pública lançou em 2015 o Manifesto em defesa da educação pública. Diferentemente do Manifesto à nação (2018), é composto por inúmeras associações e representações variadas da sociedade civil. Elas apontam no documento os indicadores da educação superior no país, o futuro das universidades brasileiras, o fosso de investimentos a que já estávamos caminhando, principalmente pelo lobby do setor privado que consome a maior fatia de investimento público 
em educação, conforme atenta o documento aos desafios da democratização do acesso à educação superior de qualidade. No documento, Luiz Schuch (UFPel) observa:

\begin{abstract}
nas universidades a preservação de componentes coloniais bastante profundos, dos quais não nos desprendemos. O mercado não é capaz de resolver os problemas educacionais de qualquer nação, muito menos de um país como o Brasil. As nossas universidades federais e estaduais estão sob ataque. O setor de serviços é a 'bola da vez' da expansão do capital. O Prouni (Programa Universidade Para Todos) é uma gigantesca política de renúncia fiscal, ao liberar capitais para investir em educação. Há uma avidez de mercado pelo setor. O Reuni (Programa de Apoio a Planos de Reestruturação e Expansão das Universidades Federais) foi expansão com aumento, com precarização. Crescimento não é por si emancipatório e não garante o papel universitário. (SCHUCH, 2015, Jornal Unifesp, Edição Especial).
\end{abstract}

Essas discussões no nível de acesso, garantia de educação como bem público, o que inclui a de nível superior, processos qualitativos e ampliação do número de vagas é algo que não está na agenda e pautas do atual governo. E as condições em que se desenvolve a linguagem sobre educação demonstra uma estreita ligação com as reformas no ensino superior do Ato Institucional número 5 (AI-5) ${ }^{\mathrm{xvi}}$ que apregoava por uma universidade para o desenvolvimento do país, e que restringia liberdades do professor de pensar, criar e ensinar, além do acesso restritivo a modalidade de ensino. Paulo Carrano (2018), professor da Universidade Federal Fluminense (UFF), observa, ao comparar o AI-5 ao projeto 'Escola sem Partido', que ambos possuem semelhanças nos seus fundamentos, como, por exemplo, o "efeito do AI-5 na educação é político do ponto de vista de calar a organização e abrir o campo cada vez mais para o setor privado, que vai encontrar na educação uma fonte de lucro".

Do mesmo modo indica o documento do Manifesto à nação, quando esclarece a necessária intervenção de setores de direito privado nos sistemas de governança e parcerias, como quando no item 4.1 Mérito, em que deixa clara sua posição contra o amplo direito de acesso ao ensino:

democratismo comunista é a destruição do ensino de qualidade, pois, quanto mais ideológico, mas ele se torna improdutivo, ineficiente e corrupto. O populismo educacional gerou incompetentes em todas as profissões, e as pessoas só conseguem superar esse atraso quando resistem a essa pressão e estudam por si mesmas (MANIFESTO À NAÇÃO, 2018, p. 53).

A delimitação dos valores incutidos neste quarto eixo incorre em uma série de atos inconstitucionais dos quais se contrapõe às diretivas estabelecidas na Lei de Diretrizes e Bases, $n^{\circ}$ 9.394/96. No tópico "Mérito: A Base de um Sistema Educacional de Sucesso" é possível apreender o conteúdo ideológico propagado pelos diferentes entes inseridos no jogo de disputa política e podem ser assim delimitadas as propostas: uma está vinculada a ala liberal do Governo, assumindo a dimensão da valorização do ser 
mediante a configuração do esforço e do mérito, fatores esses determinantes ao sucesso na vida profissional. Outra está relacionada aos interesses de setores de igrejas evangélicas, ocupadas numa empreitada de combate ao marxismo cultural que, em tese, seria propagado nas escolas, e que essa teoria estaria comprometida com a prática da intolerância aos valores morais e culturais estabelecidos pelas diferentes alas dos movimentos neopentecostais. Em excerto do referido documento é possível perceber princípios como:

valorizar e incentivar o mérito em todo o sistema educacional nacional como condição do sucesso individual e, por extensão, no sucesso do Brasil. A tragédia que se instituiu no Brasil nas últimas décadas teve como uma das causas o desprezo pelo esforço, pelo estudo, pelo mérito conquistado ao longo do tempo, em benefício do caminho mais curto da demagogia, do uso político-partidário das escolas e universidades públicas, que se tornaram instrumentos ideológicos que preparam os jovens para a Revolução Comunista, para a ditadura totalitária a exemplo da União Soviética e demais regimes sanguinários (MANIFESTO À NAÇÃO, 2018, p. 53).

Assim a configuração do discurso político estabelecido por esses grupos entende a educação como um sistema sustentável somente no processo de ingresso mediante o sistema da meritocracia, ou seja, na restrição de direitos.

Do mesmo modo, as reformas, tanto a de 1968 quanto a proposta em 2018/19, desconsideram o processo educacional e suas estruturas, assim como estipula de modo autoritário as áreas de concentração de recursos e investimentos, como vemos no item 4.3. O novo ensino superior brasileiro, em que o intuito é "Libertar a Pós-graduação, Mestrado e Doutorado da repressão aos professores pela CAPES. Rever todos os métodos de uso do dinheiro público. Rever o Ensino Superior e modernizar a Graduação" de modo que "o Brasil precisa trabalhar em duas frentes complementares: o desenvolvimento das commodities, e o desenvolvimento das patentes tecnológicas” (MANIFESTO À NAÇÃO, 2018).

O Manifesto claramente sugere o desinvestimento no setor educacional, isto é, a redução de custos, principalmente no ensino público, a precarização do trabalho docente, a otimização do tempo do trabalho do professor com atividades intrínsecas à sala de aula, e disponibilizando recursos para uma revisão e auditoria dos programas sociais que produzem acesso às universidades privadas e às bolsas de estudos do processo de ingresso no ensino superior.

\section{Considerações finais}

Todos os componentes apresentados acima dialogam com as apresentações iniciais do documento: privatizações, sistemas de parcerias, formação para o mercado de trabalho e um estado não intervencionista na regulação dos direitos assegurados constitucionalmente. Ademais, um processo intervencionista na 
educação pautado pela moralidade, como quando se reitera a ideia "ensino formal como instrução pública é essencial, contudo, de pouca valia tem se não conseguir transmitir e incutir nas crianças, adolescentes e jovens algo imaterial como o espírito reto na direção da moralidade" (MANIFESTO À NAÇÃO, p. 56).

Tal documento está na base do governo de Jair Bolsonaro que, alimentado por associações fundamentalistas religiosas, fere a liberdade religiosa e a figura jurídica da laicização que constitucionalmente rege nosso Estado entre outros fatores da política internacional. Principalmente assegura a hegemonia do setor educacional e suas diretrizes a um engessamento do acesso e da diversificação dos conteúdos e conceitos do fazer educacional, ou seja, clara afronta ao estado da educação como direito público subjetivo, pois afeta o desenvolvimento da pessoa, da expansão e desenvolvimento pelo exercício da cidadania. Apregoada pelas pessoas à frente do Ministério da Educação, é reforçada uma política de exclusão ao acesso à educação superior de qualidade e pública. Arregimenta também para a educação base uma cartilha atrelada à religiosidade, precarização e ao militarismo, abertamente desvinculada e incompatível aos preceitos constitucionais da educação e da laicidade.

Nesse sentido, uma corrente de forças entre os atores sociais, podendo ou não ter a representatividade da população e, desde a produção da Constituição findada em 1988, busca ter força política frente às condições econômicas que a levaram ao direito de fala ${ }^{\mathrm{xvii}}$. E compreende agora, no espaço entre disputas da hegemonia econômica mundial, ter não apenas esse direito, mas estendê-lo e monopolizálo para manter-se no poder, bem como evitar as manifestações de cunho social em torno das regulações e transformações do mundo do trabalho e da pluralidade na formação do cidadão.

A partir do preâmbulo estabelecido na Constituição de 1988 do Estado brasileiro, vemos a garantia de participação da sociedade, ou democracia participativa. Esse instrumento fundamental do constitucionalismo oferece mecanismos participativos através das esferas legislativa, jurídica e executiva do Estado, que são órgãos com amplos aspectos de representatividade e que serão moderadores dos anseios sociais e individuais, e das determinações econômicas, políticas e estruturais da nação brasileira (SARMENTO, 2002).

No artigo $5^{\circ}$, parágrafo $1^{\circ}$ da Constituição Federal: "as normas definidoras dos direitos e garantias fundamentais têm aplicação imediata, portanto não há caráter de natureza que possa ultrapassar ou subjugar as bases do direito de caráter absoluto" (BRASIL,1988), conforme explana o Ministro Celso de Mello abaixo:

OS DIREITOS E GARANTIAS INDIVIDUAIS NÃO TÊM CARÁTER ABSOLUTO. Não há, no sistema constitucional brasileiro, direitos ou garantias que se revistam de caráter absoluto, mesmo porque razões de relevante interesse público ou exigências derivadas do princípio de convivência das liberdades legitimam, ainda que excepcionalmente, a adoção, por parte dos órgãos estatais, de medidas restritivas das prerrogativas individuais ou coletivas, desde que respeitados os termos estabelecidos pela própria Constituição. $\mathrm{O}$ 
estatuto constitucional das liberdades públicas, ao delinear o regime jurídico a que estas estão sujeitas - e considerado o substrato ético informa — permite que sobre elas incidam limitações de ordem jurídica, destinadas, de um lado, a proteger a integridade do interesse social e, de outro, a assegurar a coexistência harmoniosa das liberdades, pois nenhum direito ou garantia pode ser exercido em detrimento da ordem pública ou com desrespeito aos direitos e garantias de terceiros. (JURISPRUDÊNCIA: STF, PLENO, RMS 23.452/RJ, RELATOR MINISTRO CELSO DE MELLO, DJ de 12.05.2000, p. 20).

Ocorre que o Estado, mesmo com a Constituição Cidadã, toma formas do próprio processo histórico em que foi gestado. No caso do atual governo e do referido Manifesto à nação, vemos claramente a desconsideração dos preceitos constitucionais e éticos, a afirmação de medidas restritivas ao direito e as prerrogativas individuais ou coletivas, em detrimento da garantia do Lobby em que está alicerçado.

Assim surge uma abismal distância do poder das camadas menos favorecidas, a manutenção da tradicional e excludente política brasileira, uma disputa política retrógrada, que carrega consigo uma perniciosa desvantagem educacional, econômica e social. E apesar de termos uma constituição produzida com muita luta e de claras feições democráticas, ela tem sido ceifada. Do mesmo modo as mudanças significativas e urgentes na sociedade brasileira, na qual os sistemas representativos têm a mesma morosidade e ingerência na adaptabilidade e aplicabilidade das demandas dos direitos fundamentais da sociedade e estão fincados nas mesmas estruturas de acesso ao poder das gerações pregressas. Isso, em termos gerais, leva-nos a interpretação de que o Manifesto à nação e os dirigentes políticos de nosso atual cenário encaminham a nação brasileira para um presente e futuro de amplo retrocesso e desigualdades, que tendem a se aprofundar a medida que os preceitos jurídico constitucionais são desrespeitados e violados, tal como exemplificados aqui pela análise do referido documento e o contexto de sua instrumentalização no setor educacional brasileiro.

\section{Referências bibliográficas}

BOBBIO, Norberto. Cultura laica y laicismo. Disponível em: <http://iviva.org/revistas/222/222-50BOBBIO.pdf>. Acesso em: 19 mar. 2019.

BOURDIEU, Pierre. Sobre o poder simbólico. In: O poder simbólico. Trad. Fernando Tomaz. Rio de Janeiro: Bertrand Brasil, 1998.

BRANCHO, Carmem. V. Laicidad y Estado moderno: definiciones y procesos. Disponível em: 〈www.produccioncientifica.luz.edu.ve/index.php/.../14389>. 2005. Acesso em: 21 mar. 2019.

BRASIL. Constituição de República Federativa do Brasil de 1988. Brasília, DF, Senado, 1988. Disponível em: 〈www.planalto.gov.br/ccivil 03/Constituicao/Constituicao.html〉. Acesso em: 21 de mar. de 2019. 
BURCKHART, Thiago. Constitucionalismo, direitos humanos e laicidade: Neopentecostalismo e política no Brasil contemporâneo. Revista Eletrônica Direito e Política, Programa de Pós-Graduação Stricto Sensu em Ciência Jurídica da UNIVALI, Itajaí, v. 13, n. 1, $1^{\text {o }}$ quadrimestre de 2018. Disponível em: 〈www.univali.br/direitoepolitica $>$. Acesso em: 21 mar. 2019.

CARRANO, Paulo. Toda ditadura quer controlar o campo educacional, porque é nele que há liberdade para pensar e construir novos caminhos para a sociedade. Disponível em: <https://paulocarrano.blog/2018/12/13/entrevista-paulo-carrano-toda-ditadura-quer-controlar-o-campoeducacional-porque-e-nele-que-ha-liberdade-para-pensar-e-construir-novos-caminhos-para-a-sociedade/>. Acesso em: 23 mar. 2019.

CHARTIER, Roger. A história cultural: entre práticas e representações. Lisboa: Difel, 1990.

CHAUI. Marilena. Ideologia da competência. Belo Horizonte. Editora Autêntica, 2014.

CONGRESSO NACIONAL. Medida Provisória $\mathrm{n}^{\circ} 746$, de 2016. Disponível em: <https://www.congressonacional.leg.br/materias/medidas-provisorias/-/mpv/126992〉. Acesso em: 21 mar. 2019.

DALARI, Dalmo. Elementos da Teoria Geral do Estado. 2 ed. São Paulo: Saraiva, 1998.

DUARTE, Clarice Seixas. Direito público subjetivo e políticas educacionais. São Paulo em Perspectiva. N. 18, p. 113-118, 2004.

FREITAS, Luiz Carlos de. Militarização da educação cria uma linha direta entre escolas para pobres e prisões. Jornal GGN. 10/03/2019. Disponível em: <https://jornalggn.com.br/artigos/militarizacao-daeducacao-cria-uma-linha-direta-entre-escolas-para-pobres-e-prisoes/>. Acesso em: 22 mar. 2019.

HABERMAS. Direito e democracia: entre facticidade e validade. Volume II. Rio de Janeiro. Tempo Brasileiro, 2003 p.113-115

HEGEL, Georg. W.F. Introdução à história da filosofia. São Paulo: Abril Cultural, 1980.

LDB - Lei de Diretrizes e Bases da Educação Nacional. Disponível em: <portal.mec.gov.br/arquivos/pdf/ldb.pdf>. Acesso em: 21 mar. 2019.

INEP. Education at a glance 2018 Disponível em: <http://portal.inep.gov.br/artigo//asset_publisher/B4AQV9zFY7Bv/content/inep-divulga-nova-edicao-do-relatorio-panorama-daeducacao-destaques-do-education-at-a-glance/21206>. Acesso em: 23 mar. 2019.

FRENTE PARLAMENTAR EVANGÉLICA. Manifesto à nação. 2018. Disponível em: <https://diariodopoder.com.br/tag/frente-parlamentar-evangelica>. Acesso em: 20 mar. 2019.

MARIANO, Ricardo. Expansão pentecostal no Brasil: O caso da Igreja Universal. Estudos Avançados, São Paulo, v. 52, p. 121-138, 2004.

MARX. Karl. Grundisse: manuscritos econômicos 1857-1858. Trad. Duayer M. e Schneider. N. São Paulo: Boitempo Editorial, 2011. 
MELLO. Celso. Ministro relator Jurisprudência: STF, Pleno, RMS 23.452/RJ, DJ de 12.05.2000, p. 20. Disponível em: 〈wwww.stf.jus.br> . Publicações > Legislação Anotada. Acesso em: 21 mar. 2019.

PARO. Vitor H. A gestão da política nacional de educação: desafios contemporâneos para a garantia do direito à educação, p. 39-56. In: Gestão da política nacional de educação: desafios contemporâneos para a garantia do direito à educação / CRUZ, Rosana E., SILVA, Samara O. (Org.) - Teresina: EDUFPI, 2016. PMDB. Uma ponte para o futuro. Disponível em: <http://pmdb.org.br/wpontent/uploads/2015/10/RELEASE-TEMER_A4-28.10.15-Online.pdf>. Acesso em: 23 mar. 2019.

RUSSAR, Andrea. Brasil: A laicidade e a liberdade religiosa desde a Constituição da República Federativa de 1988. Disponível em: <http://www.egov.ufsc.br/portal/conteudo/brasil-laicidade-e-liberdade-religiosadesde-constitui\%C3\%A7\%C3\%A3o-da-rep\%C3\%BAblica-federativa-de-1988>. Acesso em: 22 mar. 2019.

SANTOS, P. Guia prático da política educacional no Brasil: Ações, planos, impactos. 2 ed. Cengage Learning, 2012.

SARMENTO, Daniel. Livres e iguais: Estudos de Direito Constitucional. São Paulo: Max Limonad, 2002. UNIFESP. Manifesto em defesa da educação pública. Jornal Entrementes especial n. 4 - abril / 2015.

Disponível em: 〈https://www.unifesp.br/.../1719-lancado-manifesto-em-defesa-da-educacao-publica $>$. Acesso em: 18 mar. 2019.

WEBER, M. O Estado Nacional e a política. In: COHN, G. (org.). Weber. Col. "Os grandes cientistas sociais". 5 ed. São Paulo: Ática. 1991.

ZUBER Valentin. A laicidade republicana em França ou os paradoxos de um processo histórico de laicização (séculos XVIII-XXI). Repúblicas: culturas e práticas: n.59|2010. Disponível em: <https://journals.openedition.org/lerhistoria/1370\#tocto2n3>. Acesso em: 23 mar. 2019.

\section{Notas:}

\footnotetext{
${ }^{\text {i }}$ Mestre em História Econômica pela FFLCH - Universidade de São Paulo. Possui Licenciatura Plena em História e Pedagogia. Atua principalmente nos seguintes temas: Mundo do Trabalho, História das Mulheres e da Família, Educação, Gênero e Trabalho, História Econômica e América Latina. Atualmente é coeditora e produtora cultural da Companhia Cultural Fagulha, educadora social e docente na Faculdade Sumaré. Email: daniellerezera@yahoo.com.br

ii Professora Mestre em Educação formada no Programa de Estudos Pós-Graduados em Educação: História, Política, Sociedade pela Pontifícia Universidade Católica de São Paulo - PUC/SP (2014). Bacharel em História na Faculdade de Ciências Sociais da PUC-SP (2006), licenciada em História pela Faculdade de Educação (2007) da mesma instituição. Atualmente compõe o corpo docente do Instituto Sumaré de Educação Superior - Faculdade Sumaré e do Instituto Mokiti Okada - Faculdade Messiânica do Estado de São Paulo. E-mail: rgdalexandre@gmail.com
} 
iii Os sistemas simbólicos diferenciam-se segundo sua instância de produção e de recepção. E a autonomia de determinado campo constitui-se na medida em que um corpo especializado de produtores de discursos se desenvolve. "O poder simbólico como poder de constituir o dado pela enunciação, de fazer ver e fazer crer (...) só se exerce se for reconhecido" (BOURDIEU, 1998, p. 14). E, deste modo, o poder simbólico é uma forma transformada e legitimada de outras formas de poder.

iv Entendemos aqui a vertente conservadora da política em seu aspecto apelativo quanto à moral e a ética cristã das quais consolida um único padrão de vida social como se fosse equivalente aos valores sociais do coletivo.

v No dia 18 de setembro de 2003 foi implementada, oficialmente, a FPE-Frente Parlamentar Evangélica com a finalidade de "influenciar as políticas públicas do governo, defendendo a sociedade e a família, no que diz respeito à moral e aos bons costumes". (Revista FPE, 2004, p. 03 apud BURKCHART, 2018, p. 408). De acordo com (BURKCHART, 2018) suas atribuições foram definidas em torno da fiscalização dos programas de governo com vista a avaliar sua aplicabilidade, em torno da tenaz interferência no processo legislativo por meio das comissões temáticas a fim de promover leis direcionadas a políticas públicas tanto na área social quanto na área econômica, desde que de acordo com os propósitos de Deus (...) Além do aspecto da moralidade, as agremiações evangélicas investiram na política partidária visando o empoderamento no espaço de competição do campo religioso, o combate à hegemonia da Igreja Católica e também a obtenção de concessão de canais de rádio e televisão, bem como de doação de terrenos públicos em troca de apoio ao governo, o crescimento do setor e sua influência se deu a partir do incremento comunicacional via os canais de comunicação de mídia e ampliação de bases nas periferias, que desassistidas no campo cultural, político e educacional, tornou-se um ambiente natural de ampliação de público e da reserva de votos.

vi Jair Bolsonaro:

"Dados iniciais revelam indícios muito fortes que a máquina está sendo usada para a manutenção de algo que não interessa ao Brasil. Sabemos que isso pode acarretar greves e movimentos coordenados prejudicando o brasileiro. Em breve muito mais informações para o bem de nosso país.

Há algo de muito errado acontecendo: as prioridades a serem ensinadas e os recursos aplicados. Para investigar isso, o Ministério da Educação junto com o Ministério da Justiça, Polícia Federal Advocacia e Controladoria Geral da União, criaram a Lava-Jato da Educação.

A agenda globalista mira a divisão de classes. Pessoas divididas e sem valores são facilmente manipuladas. Mudar as diretrizes “educacionais" implementadas ao longo de décadas é uma de nossas metas para impedir o avanço da fábrica de militantes políticos para formarmos cidadãos.

O Brasil gasta mais em educação em relação ao PIB que a média de países desenvolvidos. Em 2003 o MEC gastava cerca de R\$ 30 bi em Educação e em 2016, gastando 4 vezes mais, chegando a cerca de R\$ 130 bi, ocupa as últimas posições no Programa Internacional de Avaliação de Alunos (PISA)."

vii Cf. PMDB. Uma ponte para o futuro. Disponível em: <http://pmdb.org.br/ wp-content/uploads/2015/10/RELEASETEMER_A4-28.10.15-Online.pdf>. Acesso em 23 mar. 2019.

viii Movimento que criminaliza a educação nas bases da LDB e dos currículos escolares, assim como a atuação do professor.

ix Disponível em: <https://www.congressonacional.leg.br/materias/medidas-provisorias/-/mpv/126992>. Acesso em: 21 mar. 2019.

${ }^{x}$ O artigo 208 da Constituição de 1988 tem por princípio a seguridade do Estado frente ao oferecimento de diversas modalidades e oportunidades no sistema educacional, sendo o inciso I a garantia do ensino fundamental, obrigatório e gratuito, inclusive para os que a ele não tiveram acesso na idade própria; garante também que deve ser gratuito, independente da idade, que se inicia no tempo ideal dos 4 aos 17 anos de idade, e no seu inciso II projeta, de modo progressivo, a universalização, a obrigatoriedade e a gratuidade ao ensino médio. Entre outros incisos e parágrafos que nos orientam a ampliação da capacidade do Estado em absorver a população como um todo dentro do sistema regular de ensino e suas diversas esferas.

xi OS 8 PRINCÍPIOS-BASE DO ENSINO O artigo 206 da Constituição Federal estabelece oito princípios nos quais o ensino deve ser baseado. São eles: I - igualdade de condições para o acesso e permanência na escola; II - liberdade de aprender, ensinar, pesquisar e divulgar o pensamento, a arte e o saber; III - pluralismo de ideias e de concepções pedagógicas, e coexistência de instituições públicas e privadas de ensino; IV - gratuidade do ensino público em estabelecimentos oficiais; V valorização dos profissionais da educação escolar, garantidos, na forma da lei, planos de carreira, com ingresso exclusi vamente por concurso público de provas e títulos, aos das redes públicas; VI - gestão democrática do ensino público, na forma da lei; VII - garantia de padrão de qualidade; VIII - piso salarial profissional nacional para os profissionais da educação escolar pública, nos termos de lei federal.

xii Ideologia de Gênero: conceito aplicado por parte eclesiástica católica a partir de 1998, e adotada por conservadores religiosos desde então, a ideia é que consideram as construções históricas e sociais dos comportamentos entre os gêneros uma falácia, os aspectos que diferenciam homens e mulheres para estes grupos é algo simples, biológico. No Brasil, com o desenvolvimento de políticas públicas de combate à violência física ou de gênero contra mulher, violência sexual contra crianças e jovens e intolerâncias a violências ligadas a opções sexuais, fez com que o Ministério da Educação, desde 2014 buscasse incluir educação sexual, combate às discriminações e promoção da diversidade de gênero e orientações sexuais no Plano Nacional de Educação

Revista Interinstitucional Artes de Educar. Rio de Janeiro, V. 5 N. 2 - pag 293-312 (mai - ago 2019): "Laicidade e educação em tempos conservadores" - DOI:10.12957/riae.2019.44855 
(PNE), o que gerou uma guerra ideológica entre os entes parlamentares e a nação, criando um movimento persecutório àqueles que defendem o direito a educação de modo plural.

xiii Disponível em: <https://blogdacidadania.com.br/tag/iolene-lima/ >. Acesso em: 18 mar. 2019.

xiv Disponível em: <https://jornalggn.com.br/artigos/militarizacao-da-educacao-cria-uma-linha-diretaentre-escolas-para-pobres-e-prisoes/>. Acesso em: 22 mar. 2019.

${ }^{x v}$ Inep. Disponível em: <http://portal.inep.gov.br/artigo/-/asset_publisher/B4AQV9zFY7Bv/content/inep-divulga-nova-edicaodo-relatorio-panorama-da-educacao-destaques-do-education-at-a-glance/21206>. Acesso em: 23 mar. 2019.

xvi O Ato Institucional n. 5, AI-5, instituído em 13 de dezembro de 1968 pelo então presidente da República, general Artur da Costa e Silva visava a cassação das liberdades civis no país, e possuía um posicionamento a um modelo de desenvolvimento da educação de modo conservador, com ampla limitação da liberdade de expressão, assim como no favorecimento do capital privado no campo educacional. A reforma no ensino superior foi um "cale-se" às classes intelectuais e teve o interesse de reorganizar $o$ sistema, desmobilizar a voz no interior das instituições e criar condições para expansão do ensino privado no ensino superior e desmobilizar o acesso ao mesmo, ampliando os investimentos em educação na esfera de cursos profissionalizantes, excluindo a classe menos favorecida do processo ao acesso ao ensino superior.

xvii A tendência de participação política desses grupos evangélicos, pentecostais e neopentecostais se dá efetivamente nos anos de 1980, segundo o autor muito mais às vésperas da Constituição de 1988, precisamente foi na Assembleia Nacional Constituinte de 1987 que marcou o início do "ativismo pentecostal” na política partidária nacional, abandonando a prática de não participação política (MARIANO apud BURKCHART, 2018, p. 406-407). O intuito era ampliar o processo participativo destes grupos e barrar um Estado que se propunha a mudanças culturais e dos valores da sociedade brasileira, que poderiam ter suas tradições morais corrompidas. A grande estratégia dos congressistas evangélicos é, desde a Assembleia Nacional Constituinte, combinar em seus discursos argumentos religiosos e argumentos dotados de racionalidade política, desta forma, conquistam legitimidade política e capacidade negociativa. Entre as questões fundamentais se dá a ampla participação dos neopentecostais na formulação do Partido Republicano Brasileiro (PRB), comandado pela Igreja Universal do Reino de Deus, que hoje é uma das corporações religiosas com maior adesão e influência na sociedade brasileira. 